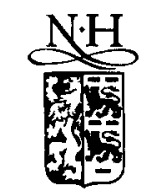

December 1997

Materials Letters 33 (1997) 129-132

\title{
Emulsion precipitation of submicron zinc oxide powder
}

\author{
Chung-Hsin Lu *, Chi-Hsien Yeh \\ Department of Chemical Engineering, National Taiwan University, Taipei, Taiwan, ROC
}

Received 17 March 1997; accepted 20 March 1997

\begin{abstract}
Ultrafine zinc oxicle powder was successfully synthesized through the emulsion precipitation process. The aqueous solution containing zinc cations was well emulsified in $n$-heptane solution, and then precipitated by adding ammonia. After calcination of the precipitates, submicron zinc oxide powder with a near spherical morphology was obtained. On comparison with the conventional precipitation method, this developed process was confirmed to be superior in preparing uniform $\mathrm{ZnO}$ powder and reducing its particle size. The emulsion stability was significantly affected by the ratio of the volume of the oil phase to that of the aqueous phase, and this ratio also influenced the mean particle size of ZnO powder. (C) 1997 Elsevier Science B.V.
\end{abstract}

PACS: 81.05.Ys; 81.10.Dn

Keywords: Synthesis; Zinc oxide; Submicron; Particles; Emulsion; Precipitation

\section{Introduction}

The emulsion process has been recently found to be one of the promising solution processes for preparing ultrafine ceramic powder having controlled morphology and composition [1]. Several research groups have successfully utilized this technique to prepare ceramic powder which contains single or multiple components [2-7]. The concept of the emulsion process is to mechanically disperse an aqueous solution containing the desirable species into an immiscible oil liquid. Through adding an appropriate surfactant and using emulsifying treatment, the aqueous solution having the desirable components can be well dispersed to form tiny droplets in the immiscible oil phase. After the emulsions are

\footnotetext{
${ }^{*}$ Corresponding author. Fax: $+886-2-3623040$.
}

prepared, two kinds of approach have been utilized for obtaining powder. One is direct evaporation and drying of the emulsions to remove the oil phase, and the other one is adding proper precipitating agents to react with the emulsified droplets for forming precipitates. The former process requires long heating time to entirely evaporate emulsions; therefore, the stability of the emulsions during heating is critical. In addition, the evaporation procedure would cause the collapse of particles to result in fragments or shallow particles $[8,9]$.

In order to synthesize solid particles, the emulsion precipitation process was adopted for preparing submicron $\mathrm{ZnO}$ powder. The effect of the volume ratio between the oil and aqueous phases on the stability of emulsions was investigated first. Then the $\mathrm{ZnO}$ powder obtained under various conditions were characterized with respect to its morphology, particle size, and size distribution. 


\section{Experimental}

The aqueous phase was prepared by dissolving zinc acetate in de-ionized water to obtain a zinc cation equal to $0.2 \mathrm{M}$. Normal heptane was used for preparing the oil-phase. For stabilizing the water-inoil (w/o) emulsions, surfactant Span-80 was added into $n$-heptane. The added amount of Span- 80 was fixed to be five volume percent of the total volume of the aqueous and oil phases. After both aqucous and the oil phases were prepared, these two phases were mixed at different ratios. After continuous mixing by a mixer at $1000 \mathrm{rpm}$ for $1 \mathrm{~h}$, homogeneous emulsions were obtained. Then $\mathrm{NH}_{4} \mathrm{OH}$ was added into the emulsion solution to precipitate zinc cations. The aging time for precipitation was $2.5 \mathrm{~h}$. The precipitates were dried in a rotary evaporator and then calcined at $700^{\circ} \mathrm{C}-1000^{\circ} \mathrm{C}$ for $2 \mathrm{~h}$. After calcination, white powders were obtained. The compounds present in calcined specimens were identified via X-ray powder diffraction (XRD) and infrared spectrometry (IR). The microstructural evolution and particle size of the specimens were examined via scanning electron microscopy (SEM).

\section{Results and discussion}

The ratio of the volume of the oil phase ( $n$ heptane) to that of the aqueous (de-ionized water) phase is defined as $R$. Fig. 1 illustrates the relation between the value of $R$ and the stable time for emulsions against phase separation. When $R$ is equal to 1 , no stable emulsion was obtained. When $R$ is 5 , the emulsion could only remain stable for $0.05 \mathrm{~h}$, and after that the oil and aqueous phases started to separate. At $R=25$, the stable emulsion time prolonged to $2 \mathrm{~h}$. The above results indicate that the stability of emulsion was significantly enhanced with an increase of $R$. Considering that the volume fraction of the aqueous phase decreases when $R$ increases, the probability for the dispersed aqueous micelles to coalesce for forming large droplets should be reduced; therefore, the stability of the aqueous micelles is enhanced. In the other experiment, the amount of the surfactant was increased up to 13 vol\% for obtaining a more stable emulsion at $R=5$. However no significant improvement was achieved.

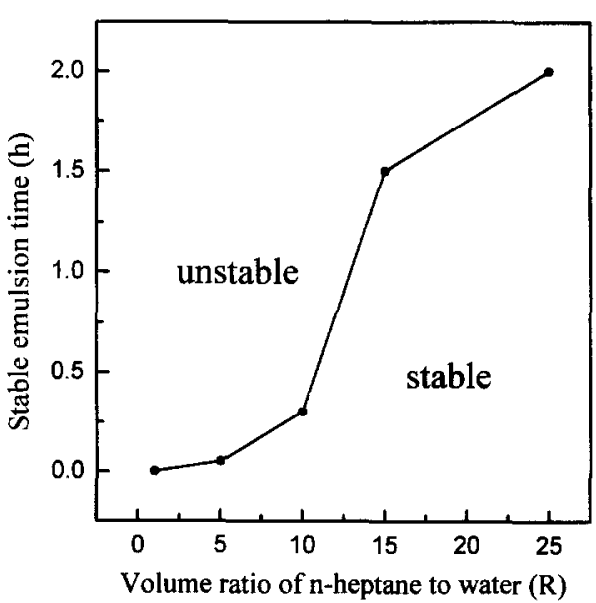

Fig. 1. The relation between the stable emulsion time and the volume ratio of $n$-heptane to water.

It seems that the value of $R$ is a more prominent factor than the amount of the surfactant in governing the emulsion stability.

After the emulsion prepared at $R=10$ was precipitated by adding ammonia, the precipitates were calcined at $400^{\circ} \mathrm{C}$. XRD analysis revealed that the calcined powder have a well-developed crystalline structure. Its XRD pattern showed great consistency with that reported in JCPDS No. 36-1451 [10], thereby it was confirmed that a hexagonal zinc oxide was obtained. On the other hand, the $400^{\circ} \mathrm{C}$-calcined powder exhibited a black color. This indicates that a part of organic species still remained in the powder, which was caused by the incomplete burning of the surfactant. On the other hand, after calcination at $700^{\circ} \mathrm{C}$ white $\mathrm{ZnO}$ powder was obtained. The diffraction intensity of the $700^{\circ} \mathrm{C}$-calcined powder was similar to that of the $400^{\circ} \mathrm{C}$-calcined powder. This reveals that the calcination at $400^{\circ} \mathrm{C}$ is sufficient for the development of the crystalline $\mathrm{ZnO}$. However, increasing the calcination temperatures is required for the complete removal of organic species.

The emulsified solutions with $R=5$ and 15 were also precipitated by ammonia. After calcination at $700^{\circ} \mathrm{C}$, similar XRD patterns were obtained. The microstructure of the $\mathrm{ZnO}$ powder obtained by $700^{\circ} \mathrm{C}$-calcination at $R=5$ is shown in Fig. 2(a). The $\mathrm{ZnO}$ powder exhibited a near spherical shape, and its particle size ranged from $0.05 \mu \mathrm{m}$ to 0.15 $\mu \mathrm{m}$ with a narrow size distribution. In the other 


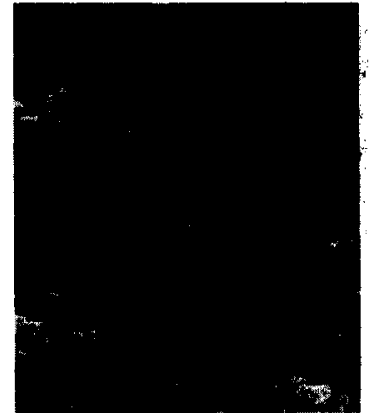

(a)

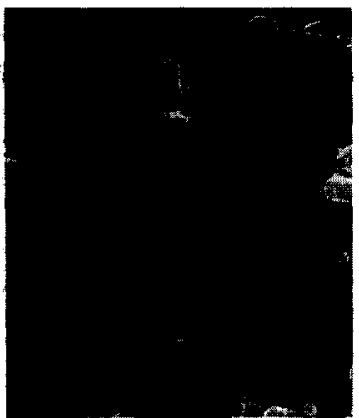

(b)
$1 \mu \mathrm{m}$

Fig. 2. Scanning electron micrographs of $\mathrm{ZnO}$ powder prepared by (a) the emulsion precipitation process at $R=5$ and (b) the conventional precipitation process.

comparative experiment, the zinc acetate solution was directly precipitated by ammonia without preparing emulsions. The prepared powder had rather a non-homogeneous morphology and the shape of particles tended to become clongated (Fig. 2(b)).

Fig. 3 illustrates the particle size of $\mathrm{ZnO}$ powder obtained at different conditions. At three values of $R$ (5, 10, and 15), the mode particle size of $\mathrm{ZnO}$ powder stayed the same; whereas, the mean particle size slightly reduced with a decrease of $R$. The mode

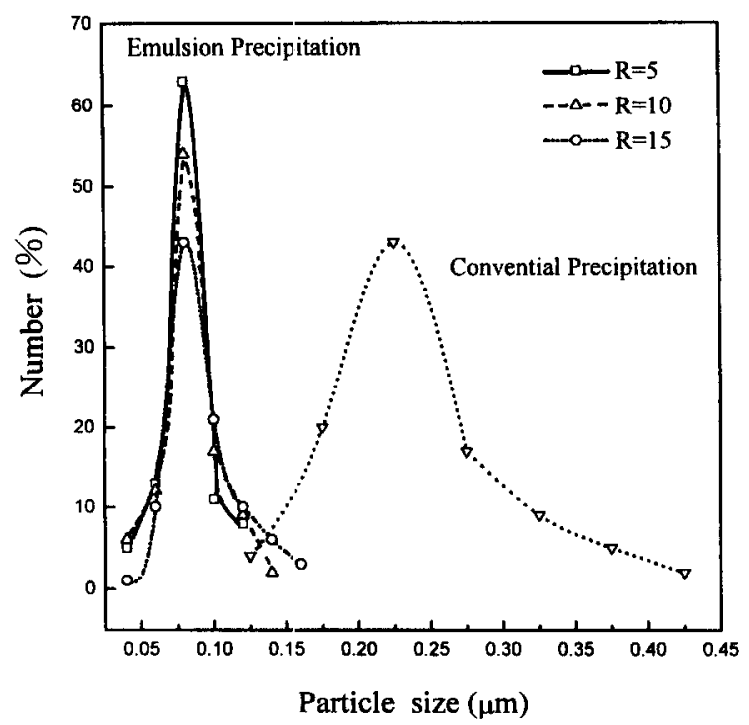

Fig. 3. Particle size distribution of $\mathrm{ZnO}$ powder prepared by the emulsion precipitation and the conventional precipitation processes. particle size was $0.080 \mu \mathrm{m}$, and the mean particle sizes for $R=5,10$, and 15 were $0.081 \mu \mathrm{m}, 0.083$ $\mu \mathrm{m}$, and $0.087 \mu \mathrm{m}$, respectively. This indicates that the preparation condition at $R=5$ resulted in the narrowest size distribution of $\mathrm{ZnO}$ powder. On the other hand, the mode and mean particle sizes of the precipitated $\mathrm{ZnO}$ powder were $0.225 \mu \mathrm{m}$ and 0.240 $\mu \mathrm{m}$ which were much larger than those of the emulsion powder. These above results demonstrated that the emulsion precipitation process, compared with the conventional precipitation, is superior in synthesizing spherical, homogeneous submicron $\mathrm{ZnO}$ powder.

At three values of $R$, the mode particle size of $\mathrm{ZnO}$ powder stayed the same. It implies that the oil to water volume ratio did not significantly vary the emulsion size. The relation between the size of the particle and that of the emulsion droplet is derived as below:

$D=d\left(\frac{\rho(1-P)}{M C}\right)^{1 / 3}$

where $D$ and $d$ are the diameters of the emulsion droplet and the particle, $\rho$ the theoretical value of the solid particle, $P$ the porosity of the particle, $C$ the cation concentration of aqueous solution, $M$ the molecular weigh of the particle. Assuming the $\mathrm{ZnO}$ particle is solid and substituting $d=0.08 \mu \mathrm{m}, \rho=$ $5.68 \mathrm{~g} / \mathrm{cm}^{3}, P=81.38 \mathrm{~g} / \mathrm{mol}, C=0.2 \mathrm{~mol} / 1$ into Eq. (1), $D=0.56 \mu \mathrm{m}$ can be obtained. This result indicates that microemulsions were formed during the process. It is also noted that although at $R=5$ the emulsion state could only maintain for $0.05 \mathrm{~h}$, fine $\mathrm{ZnO}$ powder was able to be prepared. It implies that using the emulsion precipitation process to prepare powder can avoid the problems of the instability of emulsions.

The IR spectra of the $700^{\circ} \mathrm{C}$-calcined $\mathrm{ZnO}$ powder at $R=5$ and 15 are shown in Fig. 4. At $R=15$ a large adsorption band appeared at around $450 \mathrm{~cm}^{-1}$, and several others at $840 \mathrm{~cm}^{-1}, 960 \mathrm{~cm}^{-1}$, and 1460 $\mathrm{cm}^{-1}$ were also observed. The $450 \mathrm{~cm}^{-1}$ band belongs to the characteristic band of $\mathrm{ZnO}$, and the other bands are considered to result from the remnant of the organic species from the surfactant. For the specimen at $R=5$, except for the band at 450 $\mathrm{cm}^{-1}$, the other bands became obscure. Considering 


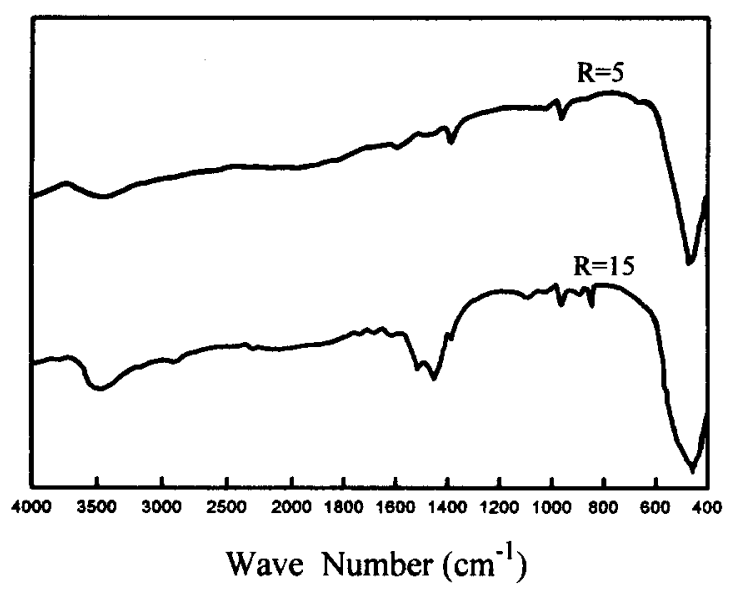

Fig. 4. IR spectra of $\mathrm{ZnO}$ powder derived from the emulsion precipitation process at $R=5$ and $R=15$.

that the amount of the surfactant was fixed at 5 vol\% of the total volume of the oil and water phases, the amount of the surfactant in solutions at $R=15$ was higher than that at $R=5$. Conclusively, Fig. 4 implies that using a large amount of surfactant in the preparation of emulsion is likely to cause problems in the burnout of the surfactant.

\section{Conclusion}

(i) $\mathrm{ZnO}$ powder was successfully synthesized by the emulsion-precipitation technique in which the aqueous solution containing zinc cations was emulsified in $n$-heptane, and later precipitated by adding ammonia.

(ii) The obtained $\mathrm{ZnO}$ powder exhibited a submicron size, and demonstrated a near spherical morphology. The particle size was much smaller than that obtained in the conventional precipitation process.

(iii) The ratio of the volume of the oil phase to that of the aqucous phase significantly affected the stability of emulsion, and influenced the mean particle size of $\mathrm{ZnO}$ powder.(iv) Adding excess amounts of the surfactant led to incomplete removal of the organic species from the calcined powder.

\section{References}

[1] G.H. Maher, C.E. Hutchins, S.D. Ross, Am. Ceram. Soc. Bull. 72 (1993) 72.

[2] K. Richardson, M. Aknic, Ceram. Inter. 14 (1988) 101.

[3] F.G. Sherif, L.J. Shyu, J. Am. Ceram. Soc. 74 (1991) 375.

[4] S.D. Ramamurthi, Z. Xu, D.A. Payne, J. Am. Ceram. Soc. 73 (1990) 2760.

[5] P. Ayyub, M.S. Multani, Mater. Lett. 10 (1991) 431.

[6] A.B. Hardy, W.E. Rhine, H.K. Bowen, J. Am. Ceram. Soc. 76 (1993) 97.

[7] C.H. Lu, Y.P. Wu, Mater. Lett. 27 (1996) 13.

[8] Y. Sarikaya, M. Akinc, Ceram. Inter. 14 (1988) 239.

[9] D.C. Vermaire, P.C. Van Berge, J. Mater. Sci. 23 (1988) 3963.

[10] Powder Diffraction File, Card No. 36-1451, Joint Committee on Powder Diffraction Standards, Swarthmore, PA. 